\title{
The Viscoelasticity and Deformation Mechanism of Taxodium Hybrid 'Zhongshanshan' Wood by Dynamic Mechanical Analysis
}

\author{
Yuehua Zhu, * Yaoli Zhang, and Biao Pan \\ The viscoelasticity of Taxodium hybrid 'Zhongshanshan' wood, while \\ undergoing hydrothermal processing, was investigated via dynamic \\ thermomechanical analysis. The results showed that the elastic \\ deformation and viscous deformation of the Taxodium hybrid \\ 'Zhongshanshan' heartwood were greater than the sapwood. The \\ heartwood average storage modulus and average loss modulus were \\ greater than the sapwood. The difference between the heartwood and \\ sapwood had little effect on the average glass transition temperature of \\ their hemicellulose, which was approximately $74^{\circ} \mathrm{C}$. The radial average \\ storage modulus was greater than the tangential, and the difference \\ between the average loss modulus in the radial and tangential directions \\ was negligible. The average glass transition temperature in the radial \\ direction was slightly lower than the tangential direction. As the moisture \\ content increased, the average storage modulus and its average \\ hemicellulose glass transition temperature decreased. The average glass \\ transition temperature tended to be lower as the moisture content \\ increased. This study revealed the structural deformation and molecular \\ movement of Taxodium hybrid 'Zhongshanshan' wood, while undergoing \\ hydrothermal processing; this has important theoretical value for \\ understanding its characteristics as well as its rational and efficient usage.
}

Keywords: Taxodium hybrid 'Zhongshanshan'; Viscoelasticity; Dynamic thermomechanical analysis; Storage modulus; Loss modulus

Contact information: College of Materials Science and Engineering, Nanjing Forestry University, Nanjing 210037 China; *Corresponding author: otakuzhu@foxmail.com

\section{INTRODUCTION}

The Taxodium hybrid 'Zhongshanshan' is an improved tree species obtained via artificial hybridization at the Institute of Botany, Jiangsu Province, and the Chinese Academy of Sciences (Shi et al. 2016). It is the product of fast-growing and salt and alkali tolerant varieties through hybridization and breeding experiments (Hua et al. 2017). Utilizing the high toughness of Taxodium hybrid 'Zhongshanshan' wood, round tubes and hollow columns with desirable axial compression properties and circumferential stiffness were developed via the spiral winding of veneers (Chen et al. 2019). Taking advantage of its good strength and rigidity properties, Taxodium hybrid 'Zhongshanshan' wood can be compounded with poplar to develop Taxodium hybrid 'Zhongshanshan' wood-poplar structural composites. This composite material is used for constructing parallel-strand lumber (PSL) wood structure buildings due to its low cost, toughness, high bearing capacity, wear resistance, and beautiful texture. However, excess temperature and humidity deforms Taxodium hybrid 'Zhongshanshan' wood during the utilization process. Moreover, considerable moisture absorption or drying severely damages the processed 
panels, and the finished products using these wood engineering materials show delamination, degumming, and relatively high deformation, which affects the market acceptance of Taxodium hybrid 'Zhongshanshan' wood (Zhu et al. 2019).

In the absence of external stress, due to the relaxation of the tiny lattices formed by the hydroxyl groups on the cellulose molecules and water molecules in the amorphous area of the wood cell wall, as well as the slippage between the cellulose hydroxyl groups in the amorphous area, the hydroxyl groups recombined in the new position via hydrogen bonding, resulting in wood deformation, characterized by viscoelasticity (Zhan et al. 2019).

Typical wood viscoelasticity performance is divided into static viscoelasticity, with creep and stress relaxation, and dynamic viscoelasticity, with hysteresis and mechanical loss under dynamic conditions. Creep is a phenomenon in which the deformation of wood gradually increases with time under constant temperature and humidity and small constant stress. Creep reflects the size and dimensional stability of a wood. The hysteresis and mechanical wood loss under dynamic conditions refers to the response of wood under the action of alternating stress or strain far lower than the yield strength it can withstand, which results in the elastic and viscous properties of a wood, expressed as the dynamic stiffness and damping performance (Afshar et al. 2020).

At the molecular level, wood is primarily composed of cellulose, hemicelluloses, and lignin. As a high polymer, wood is characterized by long and flexible cellulose chainlike structure amorphous regions in which hemicelluloses and lignin can move independently from the crystalline area. This moving unit is called a chain segment (Reiniati et al. 2015). Cellulose macromolecular chains are linear polymers composed of glucose moieties. The parallel arrangement of cellulose macromolecular chains in highdensity areas forms a well-oriented cellulose crystalline area. The molecular chain bonding is weak at low-density areas, forming amorphous regions with large gaps and irregular arrangements. Hemicelluloses are composed of amorphous polymers with short side chains of two or more types of glucose groups and acetylation of some $\mathrm{C} 6-\mathrm{OH}$ groups. Lignin is an aromatic amorphous polymer with a three-dimensional space and network structure. As a polymer with complex structures, the mechanical state and relaxation transformation complexities of wood are primarily manifested in the following points:

(1) There are crystalline and amorphous areas in wood, and the amorphous areas are constrained by the crystalline area due to the process of relaxation and transformation.

(2) Wood does not have a viscous fluid state. When the temperature rises to a certain degree, the wood undergoes pyrolysis directly without viscous flow.

(3) Glass transition occurs in the amorphous area of wood, and the modulus of elasticity slowly changes.

(4) Moisture has a considerable influence on the mechanical relaxation process of wood.

(5) Wood is anisotropic, and its viscoelasticity also varies in different directions.

(6) Wood produces a series of mechanical relaxation processes at different temperatures, making the mechanical state and the relaxation transition behavior of wood more complicated (Pang et al. 2019).

Studying the viscoelasticity of Taxodium hybrid 'Zhongshanshan' wood can reveal the structural and molecular motion during deformation and can provide an important theoretical value for understanding the properties as well as the rational and efficient usage of Taxodium hybrid 'Zhongshanshan'. 


\section{EXPERIMENTAL}

\section{Specimens}

Taxodium hybrid 'Zhongshanshan 118' was harvested from the Institute of Botany, Jiangsu Province, and the Chinese Academy of Sciences, located at the Nanjing Botanical Garden Mem. Sun Yat-Sen in Nanjing, Jiangsu (latitude 32 $32^{\prime}$ north and longitude $118^{\circ} 90^{\prime}$ east), China.

Four groups of specimens, with a size of $50 \mathrm{~mm}$ (length) $\times 10 \mathrm{~mm}$ (width) $\times 5 \mathrm{~mm}$ (thickness), were prepared. The samples were classified as radial and tangential heartwood (respectively marked as HR and HT) and radial and tangential sapwood specimens (respectively marked as SR and ST). Three specimens of each group were prepared, and there were a total of 12 specimens.

Table 1. Specimen Grouping Before Adjusting the Moisture Content

\begin{tabular}{|c|c|c|}
\hline Specimens & Saturated Salt Solution & Target Moisture Content \\
\hline MC6-HR & $\mathrm{LiCl}$ & $6 \%$ \\
\hline MC12-HR & $\mathrm{NaCl}$ & $12 \%$ \\
\hline MC18-HR & $\mathrm{KCl}$ & $18 \%$ \\
\hline MC6-HT & $\mathrm{LiCl}$ & $6 \%$ \\
\hline MC12-HT & $\mathrm{NaCl}$ & $12 \%$ \\
\hline MC18-HT & $\mathrm{KCl}$ & $18 \%$ \\
\hline MC6-SR & $\mathrm{LiCl}$ & $6 \%$ \\
\hline MC12-SR & $\mathrm{NaCl}$ & $12 \%$ \\
\hline MC18-SR & $\mathrm{KCl}$ & $18 \%$ \\
\hline MC6-ST & $\mathrm{LiCl}$ & $6 \%$ \\
\hline MC12-ST & $\mathrm{NaCl}$ & $12 \%$ \\
\hline MC18-ST & $\mathrm{KCl}$ & $18 \%$ \\
\hline
\end{tabular}

\section{Methods}

Adjusting the moisture content of the specimens

One specimen per group was placed on a sealer filled with $\mathrm{LiCl}$ saturated salt solution, $\mathrm{NaCl}$ saturated salt solution, or $\mathrm{KCl}$ saturated salt solution. All the sealers were placed in a room with a constant temperature of $16{ }^{\circ} \mathrm{C}$ until the sample reached a constant mass. Put an industrial hygrometer in each sealer to measure the humidity that reached equilibrium at $16{ }^{\circ} \mathrm{C}$.

\section{Measurement of the wood moisture content}

Before the dynamic thermomechanical testing, the specimens were removed from the sealer, and the mass $(W \mathrm{bt})$ was recorded. After the dynamic thermomechanical testing, the specimens were immediately removed from the fixture, and the mass $\left(W_{\text {at }}\right)$ was recorded. Then, the specimens were oven-dried in a convection drying oven, and their oven-dry mass $\left(W_{0}\right)$ was recorded. The moisture content was calculated using Eq. 1,

$$
M(\%)=\frac{W \mathrm{n}-W 0}{W 0} \times 100
$$

where $W_{\mathrm{n}}(\mathrm{mg})$ is the mass of $W_{\mathrm{bt}}(\mathrm{mg})$ or $W_{\mathrm{at}}(\mathrm{mg})$, and $W_{0}(\mathrm{mg})$ is the oven-dry mass.

\section{Dynamic Thermomechanical Analysis}

Vernier calipers measured the dimensions of the specimens with their adjusted moisture content in three directions (length, width, and thickness). A Q800 DMA (TA 
Instruments, New Castle, DE) was used for the dynamic thermomechanical tests. The specimens were fixed on the fixture in single cantilever mode, and the primary parameters of the DMA were as follows: a frequency of $1 \mathrm{~Hz}$, a temperature range of $-60{ }^{\circ} \mathrm{C}$ to 150 ${ }^{\circ} \mathrm{C}$, and a heating rate of $3.00{ }^{\circ} \mathrm{C} / \mathrm{min}$.

\section{RESULTS AND DISCUSSION}

\section{Moisture Content}

Table 2 shows the relative humidity of the saturated salt solution in the sealer and the moisture content of the specimens at $16{ }^{\circ} \mathrm{C}$. According to the measured oven dried mass of the specimens, the moisture content of Taxodium hybrid 'Zhongshanshan' wood at a relative humidity of $11 \%, 75 \%$, and $88 \%$ at $16{ }^{\circ} \mathrm{C}$ were $5.5 \%, 11.8 \%$, and $18.1 \%$, respectively.

Table 2. Relative Humidity and Moisture Content of the Saturated Salt Solutions

\begin{tabular}{|c|c|c|c|}
\hline $\begin{array}{c}\text { Saturated Salt } \\
\text { Solution }\end{array}$ & Temperature $\left({ }^{\circ} \mathrm{C}\right)$ & Relative Humidity (\%) & Moisture Content (\%) \\
\cline { 1 - 3 } $\mathrm{LiCl}$ & \multirow{2}{*}{$16{ }^{\circ} \mathrm{C}$} & 11 & 5.5 \\
\cline { 1 - 1 } $\mathrm{NaCl}$ & & 75 & 11.8 \\
\cline { 1 - 1 } & & 88 & 18.1 \\
\cline { 3 - 4 } & & & \\
\cline { 3 - 4 } & &
\end{tabular}

A comparison of the oven dried mass and the mass after the dynamic thermomechanical test of the specimens confirmed that as the temperature was increased from $-60{ }^{\circ} \mathrm{C}$ to $150{ }^{\circ} \mathrm{C}$ (at a heating rate of $3.00{ }^{\circ} \mathrm{C} / \mathrm{min}$ ), the specimen was dried during the dynamic thermomechanical test.

\section{Typical Storage Modulus and Loss Modulus of Taxodium hybrid 'Zhongshanshan' wood}

Figures 1 and 2 show the typical storage modulus and loss modulus temperature spectrum of Taxodium hybrid 'Zhongshanshan' wood (the sapwood specimens with a moisture content of $11.8 \%$ in the radial direction). As the temperature increased, the storage modulus of the Taxodium hybrid 'Zhongshanshan' wood showed a downward trend. At low temperatures, the energy of the molecular movement in the cell wall was extremely low. Only some small-sized units, e.g., side groups, branches, main chains, various functional groups, and individual chain links on the branches, could move, and the storage modulus was large. As the temperature increased, the molecular thermal movement energy in the cell wall gradually increased, and the chain segment, either partially or entirely, gradually began to move, which decreased the storage modulus (Pecoraro et al. 2019).

Considering the temperatures that may be encountered in the use and processing of wood, selected -60 to $150{ }^{\circ} \mathrm{C}$ degrees as the research range. The Taxodium hybrid 'Zhongshanshan' wood has two loss peaks (loss peak $\alpha$ and loss peak $\beta$ ) within the temperature range of -60 to $150{ }^{\circ} \mathrm{C}$ (Fig. 2), which indicated that two mechanical relaxation processes had occurred. Diverse types of hemicelluloses have different molecular masses and are independent of each other, as such low-molecular-mass hemicelluloses have a lower glass transition temperature. Therefore, the $\alpha$ mechanical relaxation process could be due to the glass transition of the relatively low-molecular-weight hemicelluloses (Li et al. 2020). An additional loss peak ( $\beta$ ) appeared at an approximate temperature of $0{ }^{\circ} \mathrm{C}$. 


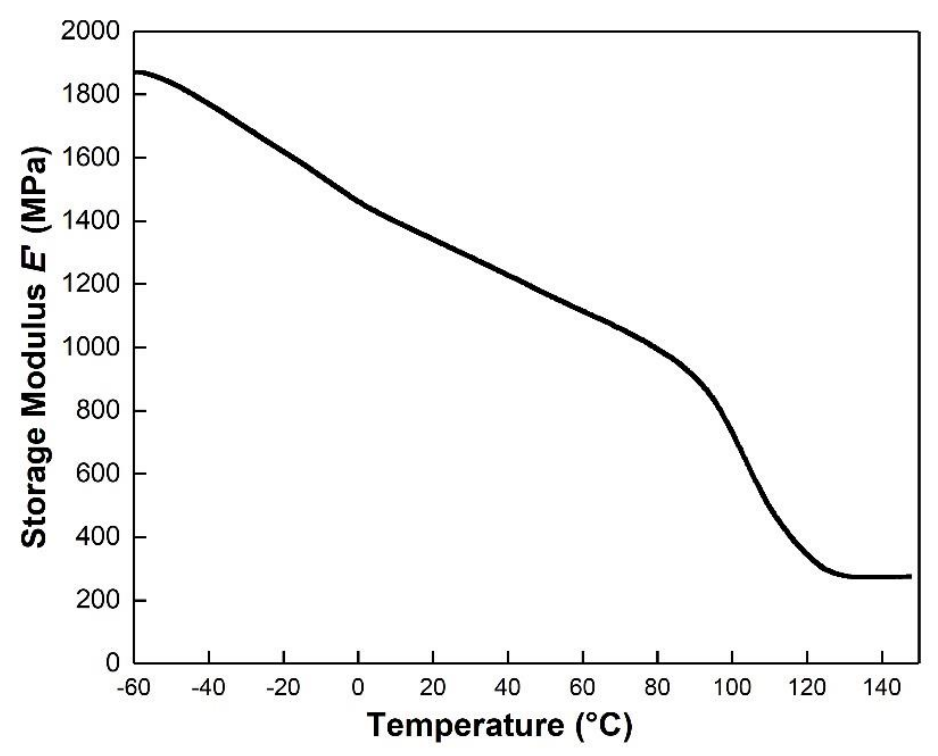

Fig. 1. Typical Storage modulus of Taxodium hybrid 'Zhongshanshan'

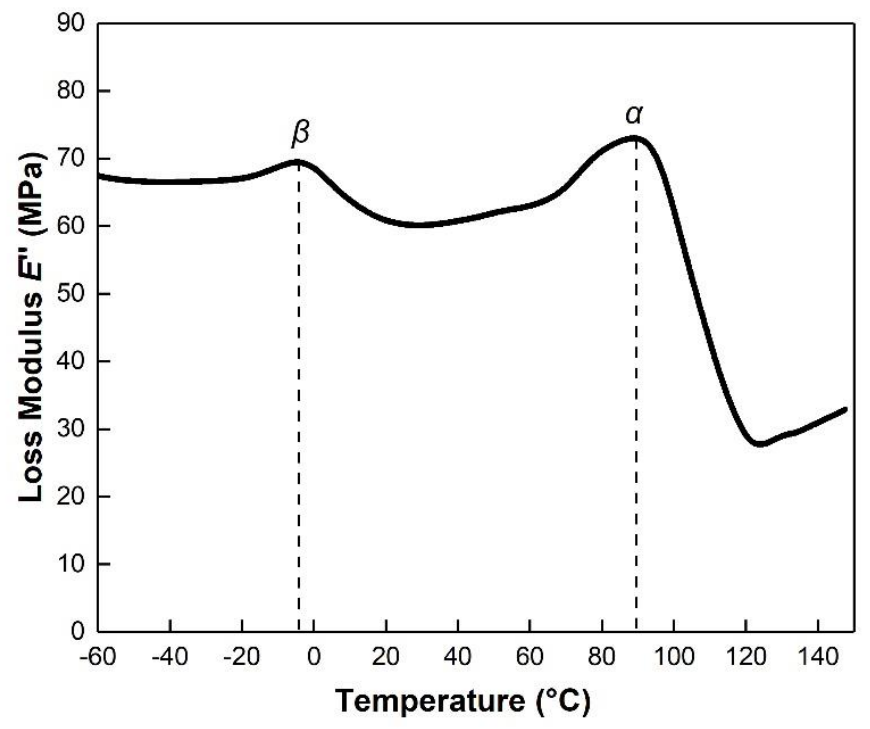

Fig. 2. Typical loss modulus of Taxodium hybrid 'Zhongshanshan'

Considering the relationship between this loss peak and temperature, this peak was not affected by wood structure or moisture changes. Results of this study suggest that the mechanical relaxation process of loss peak $\beta$ is related to the transition of the water state in wood. Liquid nitrogen was used for cooling during the test. In addition, Taxodium hybrid 'Zhongshanshan' wood cell cavities are large and thin. During the test, the water vapor in the instrument environment absorbs moisture or desorbs it from the wood. During the cooling process, the water vapor solidified inside the cell, forming ice crystals. The ice crystals were not enough to fill the cell gaps; thus, when the temperature rose, the solid water gradually melted into liquid, showing a mechanical relaxation process. 


\section{Effect of the Wood Structure on the Viscoelasticity}

Using $20^{\circ} \mathrm{C}$ as the standard temperature, the average storage modulus $\left(E^{\prime}\right)$ and average loss modulus $\left(E^{\prime \prime}\right)$ as well as the average temperatures of the two loss peaks ( $\alpha$ and $\beta$ ) were obtained.

Table 3. Viscoelasticity Comparison Between the Heartwood and Sapwood of Taxodium Hybrid 'Zhongshanshan' Wood

\begin{tabular}{|c|c|c|c|c|}
\hline Region & $\begin{array}{c}\text { Average Storage } \\
\text { Modulus }(E) \text { at } \\
\text { Standard Temperature } \\
(\mathrm{MPa})\end{array}$ & $\begin{array}{c}\text { Average Loss } \\
\text { Modulus }\left(E^{\prime}\right) \text { at } \\
\text { Standard } \\
\text { Temperature }(\mathrm{MPa})\end{array}$ & $\begin{array}{c}\text { Average } \alpha \\
\text { Peak } \\
\text { Temperature } \\
\left({ }^{\circ} \mathrm{C}\right)\end{array}$ & $\begin{array}{c}\text { Average } \beta \\
\text { Peak } \\
\text { Temperature } \\
\left({ }^{\circ} \mathrm{C}\right)\end{array}$ \\
\hline Heartwood & 1331 & 62 & 73 & -4 \\
\hline Sapwood & 1268 & 56 & 74 & -3 \\
\hline
\end{tabular}

Table 3 shows that at standard temperature $\left(20^{\circ} \mathrm{C}\right)$, both the average storage modulus and average loss modulus of the heartwood were greater than that of the sapwood. This showed that both the elastic deformation and viscous deformation of the heartwood were larger than the sapwood at standard temperature. Regarding the differences in viscoelasticity of heartwood and sapwood, some studies indicated that the primary reason for this difference is that the deposition of wood extracts limits the activity of lignins in the cell wall, so the heartwood enables the storage of more energy (Hamdan et al. 2011). The heartwood of Taxodium hybrid 'Zhongshanshan' wood contains juvenile wood. The chemical composition, microfibril angle, fiber morphology, and crystallinity of juvenile wood differs from mature wood, making the viscoelasticity of heartwood and sapwood different. The difference between the heartwood and sapwood did not affect the $\alpha$ and $\beta$ loss peaks. The average hemicellulose glass transition temperature of the heartwood and sapwood of Taxodium hybrid 'Zhongshanshan' wood were both approximately $74{ }^{\circ} \mathrm{C}$ (Sharma et al. 2015).

The radial and tangential average storage modulus $\left(E^{\prime}\right)$ and average loss modulus (E') of Taxodium hybrid 'Zhongshanshan' wood and the average temperatures of the $\alpha$ and $\beta$ loss peaks are shown in Table 4 .

Table 4. Viscoelasticity Comparison Between the Radial and Tangential of Taxodium Hybrid 'Zhongshanshan' Wood

\begin{tabular}{|c|c|c|c|c|}
\hline Region & $\begin{array}{c}\text { Average Storage } \\
\text { Modulus }(E) \text { at } \\
\text { Standard } \\
\text { Temperature }(\mathrm{MPa})\end{array}$ & $\begin{array}{c}\text { Average Loss } \\
\text { Modulus }\left(E^{\prime \prime}\right) \text { at } \\
\text { Standard } \\
\text { Temperature }(\mathrm{MPa})\end{array}$ & $\begin{array}{c}\text { Average } \alpha \\
\text { Peak } \\
\text { Temperature } \\
\left({ }^{\circ} \mathrm{C}\right)\end{array}$ & $\begin{array}{c}\text { Average } \beta \\
\text { Peak } \\
\text { Temperature } \\
\left({ }^{\circ} \mathrm{C}\right)\end{array}$ \\
\hline Radial & 1335 & 60 & 69 & -3 \\
\hline Tangential & 1264 & 58 & 75 & -4 \\
\hline
\end{tabular}


Table 4 shows that at a standard temperature $\left(20^{\circ} \mathrm{C}\right)$, the radial storage average modulus of Taxodium hybrid 'Zhongshanshan' wood was greater than the tangential, and the radial average loss modulus was equivalent to the tangential. This indicated that the radial elastic deformation was greater than the tangential, and the difference in viscous deformations between the radial and tangential directions was minimal. The primary component of Taxodium hybrid 'Zhongshanshan' wood is tracheids. Viewed from a crosssection, the higher density latewood tracheids and the lower density earlywood tracheids are connected in series in the radial direction, while the earlywood tracheids and latewood tracheids are connected in parallel in the tangential direction (Zhu et al. 2019). In addition, wood rays are arranged in the radial direction and spatially staggered with the tracheids, enhancing the rigidity of the wood. Meanwhile, the pits on the wood tracheids are primarily distributed on the radial wall, and the pits on the tracheids are bordered pits. The cell wall is thicker around the pit openings to form pit margins, making the microfibrils on the surrounding cell walls turn around. This increases the rigidity of the radial tracheid wall and improves the radial stiffness of the wood. The average temperature corresponding to the $\alpha$ loss peak in the radial direction was slightly lower than the tangential direction. Generally, materials with a large storage modulus have a higher loss peak temperature during the mechanical relaxation process (Sharma et al. 2015). Application of an external force to Taxodium hybrid 'Zhongshanshan' wood stressed the earlywood and latewood in a tangential direction, and the data obtained was a combination of earlywood and latewood. In the radial direction, the lower density earlywood changed first, and most of the data obtained came from earlywood. Therefore, the loss peak temperature of the radial specimen was slightly lower than the loss peak temperature of the tangential specimen (Backman and Lindberg 2001).

\section{Effect of Wood Moisture Content on the Viscoelasticity}

The average storage modulus ( $\left.E^{\prime}\right)$ and the average loss modulus ( $E$ ' ') of Taxodium hybrid 'Zhongshanshan' wood at different moisture contents and average $\alpha$ and $\beta$ loss peak temperatures are shown in Table 5.

Table 5. Viscoelasticity Comparison Between the Different Moisture Contents of Taxodium Hybrid 'Zhongshanshan' Wood

\begin{tabular}{|c|c|c|c|c|}
\hline $\begin{array}{c}\text { Moisture } \\
\text { Content } \\
(\%)\end{array}$ & $\begin{array}{c}\text { Average Storage } \\
\text { Modulus }(E) \text { at Standard } \\
\text { Temperature }(\mathrm{MPa})\end{array}$ & $\begin{array}{c}\text { Average Loss Modulus } \\
\left(E^{\prime}\right) \text { at Standard } \\
\text { Temperature }(\mathrm{MPa})\end{array}$ & $\begin{array}{c}\text { Average } \alpha \\
\text { Peak } \\
\text { Temperature } \\
\left({ }^{\circ} \mathrm{C}\right)\end{array}$ & $\begin{array}{c}\text { Average } \beta \\
\text { Peak } \\
\text { Temperature } \\
\left({ }^{\circ} \mathrm{C}\right)\end{array}$ \\
\hline 5.5 & 1600 & 55 & 94 & -4 \\
\hline 11.8 & 1400 & 55 & 74 & -4 \\
\hline 18.1 & 886 & 56 & 45 & -3 \\
\hline
\end{tabular}

Table 5 shows that the average storage modulus of Taxodium hybrid 'Zhongshanshan' wood at standard temperature decreased as the moisture content increased. The average glass transition temperature of hemicelluloses decreased as the moisture content increased from $5.5 \%$ to $11.8 \%$, while the average loss modulus at standard temperature increased. When the moisture content increased from $11.8 \%$ to $18.1 \%$, the average loss modulus at standard temperature decreased.

The average storage modulus decreased as the moisture content increased. First, when the moisture content increased, the tracheids swelled. The swelling of the cell cavity 
was greater than the swelling of the cell wall, which reduces the amount of substantial material in the wood per unit volume, which caused the stiffness of the wood cell wall to decrease. Second, due to the increase in moisture content, water molecules enter the amorphous area of the cell wall. The hydrogen bonds in the water molecules and the chain segments cause the growth of the chain segments, which weakens the bonding force between the chain segments, and weakens the rigidity of the wood (Zhan et al. 2019). The average loss modulus has negligible change at standard temperature, and the moisture content at a range of $5.5 \%$ to $18.1 \%$ had no noticeable effect on the average loss modulus.

The average glass transition temperature at moisture content $5.5 \%, 11.8 \%$ and $18.1 \%$ was $94{ }^{\circ} \mathrm{C}, 74{ }^{\circ} \mathrm{C}$ and $45^{\circ} \mathrm{C}$ respectively. The average glass transition temperature of hemicellulose decreased as the moisture content increased, which indicated that the water in the wood had a "plasticizer" effect. Moisture lowers the glass transition temperature of hemicellulose. From a safety perspective, the moisture content of Taxodium hybrid 'Zhongshanshan' wood should be reduced as much as possible during usage.

\section{Dynamic Mechanical Analysis (DMA) and Viscoelasticity Deformation Mechanism}

For the dynamic mechanical analysis (DMA) of wood, a double cantilever beam mode is a widely used test method. However, poplar has a relatively high moisture content, soft texture, and low density. Fixing both ends of the specimen during the test leads to compression and densification at the fixed part of the fixture and the receiving part of the sensor during the long-term test, resulting in inaccurate test results. When the single cantilever beam mode is used for the DMA, the specimens are not compressed and the densification phenomenon does not occur, which indicates that the test results are accurate.

The hemicellulose of Taxodium hybrid 'Zhongshanshan' wood has a low glass transition temperature, which occurs at a high moisture content and standard temperature conditions, i.e., the wood undergoes viscous deformation. Afterward, as the moisture content decreased, the viscous deformation was transformed into elastic deformation, solidifying the deformation, which caused deformation in the Taxodium hybrid 'Zhongshanshan' wood. The microscopic morphology of Taxodium hybrid 'Zhongshanshan' wood is simple. As the primary body, the tracheid cavity is large and thin, and the texture is light and soft. Wood has an obvious moisture content gradient in the radial direction. The glass transition times of heartwood and sapwood in the radial and tangential directions are different, and the deformation does not proceed simultaneously, resulting in the greater deformation of Taxodium hybrid 'Zhongshanshan' wood during the drying process.

\section{CONCLUSIONS}

1. The elastic deformation and viscous deformation of the heartwood of Taxodium hybrid 'Zhongshanshan' wood were found to be greater than the sapwood.

2. At standard temperature $\left(20^{\circ} \mathrm{C}\right)$, the average storage modulus and average loss modulus of Taxodium hybrid 'Zhongshanshan' heartwood were greater than the sapwood. The structural difference between the heartwood and sapwood of Taxodium hybrid 'Zhongshanshan' wood did not affect the average glass transition temperature of hemicellulose, which was approximately $74{ }^{\circ} \mathrm{C}$. 
3. The radial average storage modulus of Taxodium hybrid 'Zhongshanshan' wood is greater than the tangential, while the difference in the average loss modulus between radial and tangential direction was negligible. The average radial hemicellulose glass transition temperature was slightly lower than the tangentia.

4. At standard temperature $\left(20^{\circ} \mathrm{C}\right)$, as the moisture content increased, the average storage modulus of Taxodium hybrid 'Zhongshanshan' wood decreased, and the average loss modulus hardly changed. The average glass transition temperature of hemicellulose decreased as the moisture content increased.

5. The hemicelluloses of Taxodium hybrid 'Zhongshanshan' wood had a low glass transition temperature, meaning the wood undergoes viscous deformation. Afterward, as the moisture content decreased, the viscous deformation was transformed into elastic deformation, solidifying the deformation, which caused the deformation of Taxodium hybrid 'Zhongshanshan' wood.

\section{ACKNOWLEDGEMENTS}

This research was supported by the National Natural Science Foundation of China (Grant No. 31971585) and by the Natural Science Foundation of Jiangsu Province of China (Grant No. BK20180774). The financial support received is gratefully acknowledged.

\section{REFERENCES CITED}

Afshar, R., Cheylan, M., Almkvist, G., Ahlgren, A., and Gamstedt, E. K. (2020). “Creep in oak material from the Vasa ship: Verification of linear viscoelasticity and identification of stress thresholds," European Journal of Wood and Wood Products 78(6), 1095-1103. DOI: 10.1007/s00107-020-01566-1

Backman, A. C., and Lindberg, K. A. H. (2001). "Differences in wood material responses for radial and tangential direction as measured by dynamic mechanical thermal analysis," Journal of Materials Science 36(15), 3777-3783. DOI: 10.1023/A:1017986119559

Chen, Y., Zhu, Y., Yang, B., Guo, Y., Pan, B., and Zhu, Y. (2019). “Axial behavior and ring stiffness of spiral winding pipe in Taxodium hybrid 'Zhongshanshan' veneer," Journal of Forestry Engineering 4(2), 43-47.

Hamdan, S., Liew, Y. L., Hasan, M., and Talib, Z. A. (2011). "Studies of monomer impregnation and polymerised in situ in wood using dynamic mechanical thermal analyser," Materials Science and Technology 27(1), 40-43. DOI: 10.1179/174328409X407542

Hua, J., Han, L., Wang, Z., Gu, C., and Yin, Y. (2017). "Morpho-anatomical and photosynthetic responses of Taxodium hybrid 'Zhongshanshan' 406 to prolonged flooding," Flora 231(6), 29-37. DOI: 10.1016/j.flora.2017.04.007

Li, Z., Jiang, J., and Lyu, J. (2020). "The orthotropic viscoelastic properties of Chinese fir wood during the temperature ramping process," Drying Technology 38(11), 14111420. DOI: 10.1080/07373937.2019.1642913

Pang, S., Liang, Y., Tao, W., Liu, Y., Huan, S., and Qin, H. (2019). "Effect of the strain rate and fiber direction on the dynamic mechanical properties of beech wood," 
Forests 10(10), 1-14. DOI: 10.3390/f10100881

Pecoraro, E., Pizzo, B., Salvini, A., and Macchioni, N. (2019). "Dynamic mechanical analysis (DMA) at room temperature of archaeological wood treated with various consolidants," Holzforshung 73(8), 757-772. DOI: 10.1515/hf-2018-0235

Reiniati, I., Osman, N. B., McDonald, A. G., and Laborie, M.-P. (2015). "Linear viscoelasticity of hot-pressed hybrid poplar relates to densification and to the in situ molecular parameters of cellulose," Annals of Forest Science 72(6), 693-703. DOI: 10.1007/s13595-014-0421-1

Sharma, M., Brennan, M., Chauhan, S. S., Entwistle, K. M., Altaner, C. M., and Harris, P. J. (2015). "Wood quality assessment of Pinus radiata (radiata pine) saplings by dynamic mechanical analysis," Wood Science and Technology 49(6), 1239-1250. DOI: $10.1007 / \mathrm{s} 00226-015-0769-\mathrm{x}$

Shi, Q., Yin, Y., Wang, Z., Fan, W., and Hua, J. (2016). "Physiological acclimation of Taxodium hybrid 'Zhongshanshan 118' plants to short-term drought stress and recovery," HortScience 51(9), 1159-1166. DOI: 10.21273/HORTSCI10997-16

Zhan, T., Jiang, J., Lu, J., Zhang, Y., and Chang, J. (2019). "Frequency-dependent viscoelastic properties of Chinese fir (Cunninghamia lanceolata) under hygrothermal conditions. Part 1: Moisture adsorption," Holzforshung 73(8), 727-736. DOI: 10.1515/hf-2018-0208

Zhan, T., Lu, J., Zhang, Y., and Chang, J. (2019). "Temperature-humidity-time equivalence and relaxation in dynamic viscoelastic response of Chinese fir wood," Construction and Building Materials 227, 116637.1-116637.9. DOI: 10.1016/j.conbuildmat.2019.08.018

Zhu, Y., Pan, B., and Zhang, Y. (2019). "Veneer warpage deformation measurement based on 3D laser scanning technology," Wood Research 64(4), 1065-1076.

Zhu, Y., Wang, X., Zhang, Y., and Pan, B. (2019). "Cell deformation of Taxodium hybrid 'Zhongshanshan' wood during the drying process," BioResources 14(3), 6219-6230. DOI: 10.15376/biores.14.3.6219-6230

Article submitted: May 30, 2021; Peer review completed: August 14, 2021; Revised version received: August 25, 2021; Accepted: August 26, 2021; Published: August 30, 2021.

DOI: 10.15376/biores.16.4.6933-6942 